\title{
A Prospective Phase I/II Study: Combination Chemotherapy with Docetaxel and Pemetrexed as Second-Line Treatment in Patients with Stage IIIB/IV Non-Small Cell Lung Cancer
}

\author{
Vinzenz Kroeber Sylke Nagel Wolfgang Schuette \\ Thomas Blankenburg
}

Department of Internal Medicine II/Krankenhaus Martha-Maria Halle-Doelau, Halle (Saale), Germany

\section{Key Words}

Pemetrexed · Docetaxel · Non-small cell lung cancer · Second-line chemotherapy ·

Combination chemotherapy

\begin{abstract}
Introduction: Two standard single-agent chemotherapy treatments (docetaxel and pemetrexed) were combined in this trial and administered as second-line treatment in patients with non-small cell lung cancer (NSCLC). The aim of this study was to evaluate the safety and feasibility of combining docetaxel with pemetrexed. Methods: Six patients were enrolled between August 2007 and March 2009 with stage IIIB/IV NSCLC. The doseescalation model included a pemetrexed infusion on day 1 of $200-300 \mathrm{mg} / \mathrm{m}^{2}$ followed by infusion of docetaxel on days 1,8 and 15 at doses from 20 to $30 \mathrm{mg} / \mathrm{m}^{2}$. Primary study endpoints included efficacy and safety variables, also progression-free, overall and 1-year survival and time to progression. Results: The study was abandoned due to adverse effects defined in the protocol. The major toxicities were all of grade 3 and included fatigue, stomatitis/mucositis, diarrhea and in one case, an episode of febrile neutropenia. Two patients died during the study, but not as a direct result of the treatment. Conclusions: We recommend that docetaxel or pemetrexed monotherapies should continue to be considered the standard second-line chemotherapy treatment against NSCLC. The results of this study
\end{abstract}

Prof. Dr. med. Wolfgang Schuette

Department of Internal Medicine II/Krankenhaus Martha-Maria Halle-Doelau Roentgenstrasse 1

DE-06120 Halle (Saale) (Germany)

E-Mail wolfgang.schuette@martha-maria.de 
warrant no further investigation into this particular combination treatment due to the severe toxicity effects encountered.

(c) 2014 S. Karger AG, Basel

\section{Introduction}

Cancer is the leading cause of death in economically developed countries, with a similar trend occurring in developing countries where the adoption of cancer-associated lifestyles such as smoking or physical inactivity is on the rise [1]. Non-small cell lung cancer (NSCLC) accounts for approximately $80 \%$ of all cases of lung cancer, and it is the most prevalent cause of cancer death among men and women worldwide [2,3]. Due to the lack of typical symptoms in the early stages, up to $70 \%$ of cancer victims already have locally advanced or metastatic disease at the point of diagnosis, which has resulted in only a third of all patients being eligible to receive curative therapy and has led to a very poor overall prognosis [4].

Platinum-based chemotherapy in combination with third-generation agents such as vinorelbine, gemcitabine, docetaxel and paclitaxel, has become the gold standard of treatment for patients with advanced NSCLC and a good performance status (PS), as it prolongs patients' lifespan and improves their quality of life [5-9]. However, some treated patients require further therapy due to eventual disease progression. In addition, there are a number of agents employed in second-line chemotherapy that have proved effective in numerous studies, in particular, docetaxel, pemetrexed and erlotinib [3, 10-12].

In two phase III trials, docetaxel provided clinical benefits to patients who had previously been treated for NSCLC $[10,13]$. The first study included patients randomized to receive either docetaxel ( 75 or $100 \mathrm{mg} / \mathrm{m}^{2}$, once every 3 weeks) or best supportive care. Median survival and 1-year survival both significantly improved from 4.6 to 7.5 months and 11 to $37 \%$, respectively. The second trial randomized patients to receive either docetaxel 75 or $100 \mathrm{mg} / \mathrm{m}^{2}$ ) or vinorelbine/ifosfamide. Median survival was similar across the three study groups, with 1-year survival reaching 32, 21 and $19 \%$ for the 75 and $100 \mathrm{mg} / \mathrm{m}^{2}$ docetaxel groups and the vinorelbine/ifosfamide group, respectively.

Pemetrexed is, among others, a multitargeted antifolate chemotherapy agent used in NSCLC treatment [14]. Its main anticancer property is achieved by inhibiting enzymes used in purine and pyrimidine synthesis [15]. A phase II study determined the efficacy of pemetrexed as a second-line treatment of advanced NSCLC, resulting in a response rate of $8.9 \%$ and median survival time of 5.7 months [16]. Hanna et al. [3] assessed a total of 571 patients and compared docetaxel and pemetrexed as second-line treatments. Results revealed equivalent effectiveness, with a response rate of $9.1 \%$ for pemetrexed compared to $8.8 \%$ for docetaxel. With 2.9 months, the median progression-free survival rate was the same for both agents [3].

Although equally effective, the therapeutic benefits of both agents are modest; hence, there is a need for alternative therapy regimens to improve the efficacy of second-line treatment of advanced NSCLC. To this end, we supposed that a chemotherapy doublet treatment incorporating both docetaxel and pemetrexed might achieve greater results. Therefore, the aim of the present study was to determine the maximum tolerated dose (MTD) and objective response rate (ORR) of this particular combination. 
Kroeber et al.: Combination Chemotherapy with Docetaxel and Pemetrexed as Second-Line Treatment in Patients with Stage IIIB/IV Non-Small Cell Lung Cancer

\section{Patients and Methods}

Key Eligibility Criteria

To be eligible to participate in the study, patients were required to: (1) be 18 years of age or over; (2) have a confirmed histological or cytological diagnosis of stage IIIB or IV NSCLC; (3) have had at least one measurable lesion per Response Evaluation Criteria In Solid Tumors (RECIST) and an Eastern Cooperative Oncology Group (ECOG) PS score of 0-2; (4) have received a maximum of one chemotherapy treatment (any prior history of surgery or radiotherapy allowed); (5) demonstrate adequate cardiac functioning [neither having unstable angina nor myocardial infarction within the previous 6 months, and no group III or IV heart failure as per the New York Heart Association (NYHA) Functional Classification], and (6) have a predicted life expectancy of at least 12 weeks. Participants were also required to have adequate hepatic (bilirubin $\leq 1.5 \mathrm{mg} / \mathrm{dl}$ ), renal (creatinine clearance $>60 \mathrm{ml} / \mathrm{min}$, serum creatinine $\leq 1.5 \mathrm{mg} / \mathrm{dl}$ ) and bone marrow (leucocytes $>1,500 / \mathrm{mm}^{3}$, thrombocytes $>100,000 / \mu \mathrm{l}$ ) functioning. Finally, participants had to be willing and able to provide written informed consent, which completed the approval process set out by the Ethics Committee.

\section{Study Design and Treatment Plan}

The study was open-labeled and incorporated two phases. Phase I included three separate compound dose regimes with 3-6 patients being enrolled on each treatment regime. The treatments were carried out in 4-week cycles $(\mathrm{q} 4 \mathrm{w})$ with pemetrexed and docetaxel being administered on day 1, and on days 1, 8 and 15, respectively (table 1). Pemetrexed was scheduled to be administered on day 1 as a 10-min intravenous infusion of either 200 or 300 $\mathrm{mg} / \mathrm{m}^{2}$ followed by a 30 -min break, then a 30 -min intravenous infusion of 20 or $30 \mathrm{mg} / \mathrm{m}^{2}$ docetaxel (see table 2 for the administration schedule). On days 8 and 15 of each cycle, only a 30-min intravenous infusion of 20 or $30 \mathrm{mg} / \mathrm{m}^{2}$ docetaxel was administered. The treatment plan was repeated for up to six cycles depending on the level of dose limiting toxicity (DLT) reached. The treatment schedule is presented in table 1 along with the concurrently administered medication, which comprised vitamin $\mathrm{B}_{12}$, folic acid and dexamethasone. Colony-stimulating factors were used at the doctor's discretion and 5-HT3 antagonists were used as antiemetics.

Phase II was conceptualized using the One-Sample Multiple Testing Procedure by Fleming 1982 [17], and was intended to be carried out on 15 to a maximum of 35 patients. This part is not further described since the study was already abandoned in phase I (see the Results section for abandonment reasons).

\section{Dose Modification}

The three compound dosage regimes for docetaxel and pemetrexed are presented in table 2. The baseline dosage was scheduled as $25 \mathrm{mg} / \mathrm{m}^{2}$ docetaxel and $200 \mathrm{mg} / \mathrm{m}^{2}$ pemetrexed, followed by $25 / 300 \mathrm{mg} / \mathrm{m}^{2}$ and $30 / 300 \mathrm{mg} / \mathrm{m}^{2}$ as the two higher dose regimes, respectively. Three patients were initially enrolled into the baseline dose regime. When at least one severe toxicity event occurred within the baseline dose regime, another 3 patients would be initiated into the same dose level. Where no further severe toxicity occurred in the same regime, or where it occurred but only in 1 patient, the next 3 patients were to be enrolled into the next higher dose level. The MTD would be reached and dose escalation would therefore not be carried out where the DLT level was reached in at least 2 of the 3 patients. The DLT limit was defined as having been reached in accordance with the following minimum criteria: grade 3/4 diarrhea; grade 3/4 rash; grade 3/4 neurotoxicity; grade 4 thrombocytopenia for more than 5 days; grade 4 leukocytopenia for more than 5 days; grade 
Kroeber et al.: Combination Chemotherapy with Docetaxel and Pemetrexed as Second-Line Treatment in Patients with Stage IIIB/IV Non-Small Cell Lung Cancer

4 neutropenia; febrile neutropenia, and any treatment delay due to toxicity [grading applied in accordance with that defined by the National Cancer Institute (NCI)].

Toxicity and Efficacy Assessments

The two primary study endpoints were efficacy and safety, which required the following parameters to be recorded 2 weeks ahead of patient enrollment: history and physical examinations, vital signs, ECOG PS, blood chemistry, complete blood counts and differential $\mathrm{X}$-rays and CT scans. With regard to safety, adverse event assessments were undertaken every 3 weeks and graded according to the National Cancer Institute Common Terminology Criteria for Adverse Events, version 3.0 (NCI CTCAE) [18]. These included detailed toxicity questionnaires, physical examinations and complete differential blood counts. Where adverse events were observed, they were recorded and, depending on the degree of severity, treatment was postponed for up to 15 days until resolution of the prohibitive toxicity was reached. Such events had to be recorded in a provided form sheet. Tumor response was planned to be assessed according to the standard RECIST criteria every two chemotherapy cycles by assessing appropriate imaging studies of the target lesions. All responses were to be confirmed by a separate imaging evaluation 4 weeks later. Additional prespecified efficacy variables included progression-free, overall and 1-year survival as well as time to progression.

\section{Results}

\section{Patient Characteristics}

Patients' characteristics are shown in table 3. A total of 6 patients were enrolled between August 2007 and March 2009 into phase I of the study. The patients' median age was 70 years and PS (ECOG) was either 0 ( 3 patients) or 1 ( 3 patients). Five were suffering from an adenocarcinoma and 1 from a squamous cell carcinoma. All 6 patients received only a single cycle of the combination chemotherapy regimen (without delay or reduction).

\section{Dose Limiting Toxicities}

Table 4 reports the DLT of all grades and shows that severe toxicities of grade 3 occurred in 5 patients, which resulted in the abandonment of therapy for 4 of them. Three patients were enrolled at the first dose level. One had an allergic reaction to docetaxel causing a rash, another showed grade 3 fatigue and grade 3 stomatitis/mucositis, and the remaining patient died after the first cycle due to disease progression. In accordance with the protocol, another 3 patients were initiated into the study under the baseline dose regime. Again, serious toxicities were reported, with 1 patient suffering grade 3 diarrhea and dying a fortnight after administration of the treatment regime, albeit without causation to the administered chemotherapy. The other 2 patients developed grade 3 stomatitis/mucositis, 1 of whom developed additional nausea, anorexia, alopecia and dyspnea, while the other experienced a grade 3 episode of febrile neutropenia.

\section{Efficacy}

Tumor response was intended to be observed using RECIST criteria after every two cycles of therapy. Since all 6 patients showed either a severe toxicity or early progression of disease, leading to early termination of the study, an accurate evaluation of tumor response was not possible. The outcome for each patient is shown in table 5. The best response for three of the six enrollees was progressive disease (PD) after less than 3 months. A best 
response for the remaining patients could not be assessed, but time to PD for 2 of them was also less than 3 months, with the remaining patient being the only 1 of all 6 for whom time to PD was greater than 3 months. As the study could not be escalated to the next dose regime, a MTD could not be met, and phase II of the study could not be started.

\section{Discussion}

For the treatment of NSCLC, pemetrexed and docetaxel have been reported as the gold standard across numerous studies; however, associated therapeutic benefits of these agents remain modest; hence, the urgent need for alternative therapy regimes to improve the efficacy of second-line treatment of the disease remains [3, 10-12]. Therefore, our study sought to combine these two agents in a single therapy regime, which unfortunately failed to demonstrate additional positive effects due to the high levels of toxicity encountered.

Doublets of pemetrexed combined with taxanes (paclitaxel and docetaxel) have been tested in clinical trials, one of which investigated the combination of pemetrexed and paclitaxel, which has been associated with promising efficacy and tolerable toxicity [19]. The recommended determined dose combination was $90 \mathrm{mg} / \mathrm{m}^{2}$ paclitaxel on days 1 and 8 , and $500 \mathrm{mg} / \mathrm{m}^{2}$ pemetrexed on day 8 in a 21-day cycle. The most common dose-limiting toxicities were febrile neutropenia and fatigue, which also occurred in our study but to a greater degree. Another trial combined the same agents that showed no evidence of pharmacokinetic interactions and demonstrated broad clinical activity to thyroid, head and neck, lung, liver, pancreas, prostate, renal, and stomach cancers [20]. Stathopoulos et al. [21] investigated the same combination with doses of $500 \mathrm{mg} / \mathrm{m}^{2}$ pemetrexed and $175 \mathrm{mg} / \mathrm{m}^{2}$ paclitaxel in treating advanced or metastatic NSCLC. The study resulted in an ORR of $39.6 \%$ associated with a median survival of 14 months, with toxicity being relatively mild at $8.3 \%$ grade 3 and 4 neutropenia along with some other very mild hematologic and nonhematologic adverse events. Compared to other trials with similar responses and median survival rates, this study is most notable for its very low toxicity profile, which contrasts with the results of our study.

Earlier clinical trials with pemetrexed often resulted in severe reactions to the chemotherapy such as hematologic toxicity, skin rash, lethargy, nausea and emesis [14, 16, 22]. It was later discovered that the concurrent administration of appropriate medication in the form of vitamin $B_{12}$ and folates helped to significantly reduce such adverse events [23], and it became standard practice in chemotherapy regimens. In spite of such general efficacy, it failed to prevent the occurrence of multiple grade 3 and 4 adverse events in our study, which led to its early termination. Choosing the weekly docetaxel schedule over the classic 3weekly schedule to lower the incidence of adverse events did not have a positive effect either $[24,25]$.

The published literature reports a very similar study to the present one, but with very different outcomes. A phase I study was conducted to determine the MTDs and the doselimiting toxicities of a combined pemetrexed and docetaxel regimen in patients with advanced unresectable or metastatic NSCLC [26]. Interestingly the MTD has not been reached and exceeded the recommended doses for the respective monotherapies. Considering that efficacy results were similar in high- and low-dose levels, a dose of $75 \mathrm{mg} / \mathrm{m}^{2}$ docetaxel and $500 \mathrm{mg} / \mathrm{m}^{2}$ pemetrexed was recommended, both administered on day 1 every 3 weeks and for up to six cycles. The following data was reported: ORR of $23 \%$, disease control rate of $39 \%$ and median overall survival of 10 months. The regime was well tolerated with neutropenia and fatigue being the most frequently observed adverse events. 
There are also a few studies that evaluated the combination of pemetrexed and docetaxel in patients with solid tumors. In a phase I study, a fixed dose of $60 \mathrm{mg} / \mathrm{m}^{2}$ docetaxel on day 8 combined with escalated doses of $300-600 \mathrm{mg} / \mathrm{m}^{2}$ pemetrexed on day 1 was tested, and the MTD was immediately reached at the first level [27]. Changing the treatment schedule by administering pemetrexed on day 15 allowed for a further escalation. Furthermore, at the time of study presentation, the MTD had not yet been reached. The regimen was well tolerated, with hematologic toxicity being the main adverse event. Another phase I study administered both agents on days 1 and 15, and again the MTD was not reached, leading to the conclusion that the combination is feasible and shows activity in a number of solid tumors [28]. Similar outcomes to our study were reported in a phase I study, which was suspended and the planned phase II trial abandoned due to the limited tolerability and efficacy [29]. Agents were given at day 1 of a 21-day cycle, and the most common grade 1-4 hematologic toxicity was anemia, while the most common nonhematologic toxicities were fatigue, nausea and constipation.

In contrast to the mainly positive outcomes of the studies cited, a meta-analysis comprising six clinical trials recommended against the use of combination chemotherapy as second-line treatment of advanced NSCLC, concluding that although response rates and progression-free survival are significantly increased, the treatment is more toxic and does not improve overall survival compared to single-agent therapy [30]. Since toxicity is particularly relevant in second-line treatment of advanced NSCLC, the potential negative impact on the benefit/risk ratio and quality of life should therefore be of greater interest.

In conclusion, our dose-escalation study demonstrates that the combination of docetaxel and pemetrexed as second-line treatment for advanced NSCLC is neither superior in efficacy nor is it physically tolerated in patients. Given its potentially detrimental effects compared to that of a single agent therapy, a pemetrexed/docetaxel doublet warrants no further investigation. Therefore, the docetaxel monotherapy should continue to be considered as the standard therapy in its usual setting.

\section{Acknowledgements}

The study was supported by Sanofi-Aventis.

The authors are grateful for the help from the study personnel and thank the patients and their families for their contributions to this study.

\section{Disclosure Statement}

Wolfgang Schuette has the following disclosures: grants, honoraria and fee for monitoring board from Sanofi Aventis. In addition, he received grants, consultancy honoraria and fee for monitoring board from Roche, Lilly, Amgen, Merck, AstraZeneca and Pfizer in the context of other clinical trials.

All other authors have nothing to disclose. 
Kroeber et al.: Combination Chemotherapy with Docetaxel and Pemetrexed as Second-Line Treatment in Patients with Stage IIIB/IV Non-Small Cell Lung Cancer

\section{References}

1 Mathers CD, Fat DM, Boerma JT: The global burden of disease: 2004 update. World Health Organization, 2008.

2 Jemal A, Bray F, Center MM, et al: Global cancer statistics. CA Cancer J Clin 2011;61:69-90.

-3 Hanna N, Shepherd FA, Fossella FV, et al: Randomized phase III trial of pemetrexed versus docetaxel in patients with non-small-cell lung cancer previously treated with chemotherapy. J Clin Oncol 2004;22:15891597.

4 Spiro SG, Gould MK, Colice GL; American College of Chest Physicians: Initial evaluation of the patient with lung cancer: symptoms, signs, laboratory tests, and paraneoplastic syndromes: ACCP evidenced-based clinical practice guidelines (2nd edition). Chest 2007;132(3 Suppl):149S-160S.

5 Scagliotti GV, Parikh P, von Pawel J, et al: Phase III study comparing cisplatin plus gemcitabine with cisplatin plus pemetrexed in chemotherapy-naive patients with advanced-stage non-small-cell lung cancer. J Clin Oncol 2008;26:3543-3551.

-6 Schiller JH, Harrington D, Belani CP, et al: Comparison of four chemotherapy regimens for advanced nonsmall-cell lung cancer. N Engl J Med 2002;346:92-98.

7 Pfister DG, Johnson DH, Azzoli CG, et al: American Society of Clinical Oncology treatment of unresectable non-small-cell lung cancer guideline: update 2003. J Clin Oncol 2004;22:330-353.

8 Hotta K, Matsuo K, Ueoka H, et al: Meta-analysis of randomized clinical trials comparing cisplatin to carboplatin in patients with advanced non-small-cell lung cancer. J Clin Oncol 2004;22:3852-3859.

-9 Hotta K, Matsuo K: Long-standing debate on cisplatin- versus carboplatin-based chemotherapy in the treatment of advanced non-small cell lung cancer. J Thorac Oncol 2007;2:96-98.

10 Shepherd FA, Dancey J, Ramlau R, et al: Prospective randomized trial of docetaxel versus best supportive care in patients with non-small-cell lung cancer previously treated with platinum-based chemotherapy. J Clin Oncol 2000;18:2095-2103.

-11 Shepherd FA, Rodrigues Pereira J, Ciuleanu T, et al: Erlotinib in previously treated non-small-cell lung cancer. N Engl J Med 2005;353:123-132.

12 Kim ES, Hirsh V, Mok T, et al: Gefitinib versus docetaxel in previously treated non-small-cell lung cancer (INTEREST): a randomised phase III trial. Lancet 2008;372:1809-1818.

13 Fossella FV, DeVore R, Kerr RN, et al: Randomized phase III trial of docetaxel versus vinorelbine or ifosfamide in patients with advanced non-small-cell lung cancer previously treated with platinumcontaining chemotherapy regimens. J Clin Oncol 2000;18:2354-2362.

14 Clarke SJ, Abratt R, Goedhals L, et al: Phase II trial of pemetrexed disodium (ALIMTA®, LY231514) in chemotherapy-naïve patients with advanced non-small-cell lung cancer. Ann Oncol 2002;13:737-741.

15 Sigmond J, Backus HHJ, Wouters D, et al: Induction of resistance to the multitargeted antifolate Pemetrexed (ALIMTA) in WiDr human colon cancer cells is associated with thymidylate synthase overexpression. Biochem Pharmacol 2003;66:431-438.

16 Smit EF, Mattson K, von Pawel J, et al: ALIMTA (pemetrexed disodium) as second-line treatment of nonsmall-cell lung cancer: a phase II study. Ann Oncol 2003;14:455-460.

17 Fleming TR: One-sample multiple testing procedure for phase II clinical trials. Biometrics 1982;38:143-151.

18 Common Terminal Criteria for Adverse Events v3.0 (Japan Clinical Oncology Group Website). http://www.jcog.jp/doctor/tool/ctcae.html (accessed February 28, 2014).

19 Hanauske A-R, Dumez H, Piccart M, et al: Pemetrexed combined with paclitaxel: a dose-finding study evaluating three schedules in solid tumors. Invest New Drugs 2009;27:356-365.

20 Graefe T, Lubbing C, Bolling C, et al: Phase I study of pemetrexed plus paclitaxel in patients with solid tumor. J Clin Oncol 2004 ASCO Annual Meeting Proceedings. Vol 22, No 14S (abstract 2103).

21 Stathopoulos GP, Dimitroulis J, Toubis M, et al: Pemetrexed combined with paclitaxel in patients with advanced or metastatic non-small-cell lung cancer: a phase I-II trial. Lung Cancer 2007;57:66-71.

22 Rusthoven JJ, Eisenhauer E, Butts C, et al: Multitargeted antifolate LY231514 as first-line chemotherapy for patients with advanced non-small-cell lung cancer: a phase II study. National Cancer Institute of Canada Clinical Trials Group. J Clin Oncol 1999;17:1194-1199.

23 Bajetta E, Celio L, Buzzoni R, et al: Phase II study of pemetrexed disodium (Alimta ${ }^{\circledR}$ ) administered with oral folic acid in patients with advanced gastric cancer. Ann Oncol 2003;14:1543-1548.

24 Schuette W, Nagel S, Blankenburg T, et al: Phase III study of second-line chemotherapy for advanced nonsmall-cell lung cancer with weekly compared with 3-weekly docetaxel. J Clin Oncol 2005;23:8389-8395.

-25 Di Maio M, Perrone F, Chiodini P, et al: Individual patient data meta-analysis of docetaxel administered once every 3 weeks compared with once every week second-line treatment of advanced non-small-cell lung cancer. J Clin Oncol 2007;25:1377-1382.

-26 Kotsakis A, Agelaki S, Vardakis N, et al: A dose-escalation study of pemetrexed and docetaxel in non-smallcell lung cancer. Cancer Chemother Pharmacol 2011;68:415-422.

27 Lopez-Martin A, Cubedo R, Garcia-Rivas I, et al: Phase I trial of the sequential administration of pemetrexed (P) and docetaxel (D) in patients (pts) with advanced solid tumours. J Clin Oncol 2005 ASCO Annual Meeting Proceedings. Part I 23. No 16S (abstract 2108). 


\section{Case Reports in Oncology}

\begin{tabular}{l|l}
\hline Case Rep Oncol 2014;7:435-443 \\
\hline DOI: $10.1159 / 000365323$ & $\begin{array}{l}\text { C 2014 S. Karger AG, Basel } \\
\text { www.karger.com/cro }\end{array}$ \\
\hline
\end{tabular}

Kroeber et al.: Combination Chemotherapy with Docetaxel and Pemetrexed as Second-Line Treatment in Patients with Stage IIIB/IV Non-Small Cell Lung Cancer

28 Garland LL, Cranmer L, Gerstner G, et al: Phase I dose escalation trial of biweekly pemetrexed in combination with docetaxel in advanced solid tumors. J Clin Oncol 2007 ASCO Annual Meeting Proceedings. Part I 25. No 18S (abstract 13019).

29 Petrylak DP, Hood K, Xu R, et al: Phase I trial of pemetrexed (P) plus docetaxel (D) in advanced malignancies. J Clin Oncol 2008 ASCO Annual Meeting Proceedings. Vol 26. No 15S (abstract 13517).

30 Di Maio M, Chiodini P, Georgoulias V, et al: Meta-analysis of single-agent chemotherapy compared with combination chemotherapy as second-line treatment of advanced non-small-cell lung cancer. J Clin Oncol 2009;27:1836-1843.

Table 1. Treatment schedule including the concurrent medication

\begin{tabular}{|c|c|c|c|c|}
\hline Date & Compound & Delivery system & Dosage & Interval \\
\hline $\begin{array}{l}1 \text { week prior to treatment start } \\
\text { until } 3 \text { weeks after therapy stop }\end{array}$ & Folate & Oral & $350-1,000 \mu \mathrm{g}$ & Daily \\
\hline 1 week prior to treatment start & Vitamin $B_{12}$ & IM & $1,000 \mu \mathrm{g}$ & Every 9 weeks \\
\hline 1 day prior to treatment start & Dexamethasone & Oral & $8 \mathrm{mg}$ & Every evening \\
\hline On day of treatment start & Dexamethasone & CVI, bolus or SI & $8 \mathrm{mg}$ & $\begin{array}{l}30 \text { min prior to docetaxel } \\
\text { infusion }\end{array}$ \\
\hline Day 1; q4w & Pemetrexed & CVI & $200-300 \mathrm{mg} / \mathrm{m}^{2}$ & $\begin{array}{l}10 \text { min infusion (followed by } \\
30 \text { min break) }\end{array}$ \\
\hline \multirow[t]{2}{*}{ Days $1,8,15 ; \mathrm{q} 4 \mathrm{w}$} & Docetaxel & CVI & $20-30 \mathrm{mg} / \mathrm{m}^{2}$ & 30 min infusion \\
\hline & Dexamethasone & Oral & $8 \mathrm{mg}$ & Every evening \\
\hline
\end{tabular}

$\mathrm{CVI}=$ Continuous intravenous infusion; $\mathrm{IM}$ = intramuscular injection; $\mathrm{SI}=$ short infusion

Table 2. Dose escalation scheme

\begin{tabular}{lccc}
\hline Compound & Baseline dosage & Escalation I & Escalation II \\
\hline Docetaxel & $25 \mathrm{mg} / \mathrm{m}^{2}$ & $25 \mathrm{mg} / \mathrm{m}^{2}$ & $30 \mathrm{mg} / \mathrm{m}^{2}$ \\
Pemetrexed & $200 \mathrm{mg} / \mathrm{m}^{2}$ & $300 \mathrm{mg} / \mathrm{m}^{2}$ & $300 \mathrm{mg} / \mathrm{m}^{2}$ \\
\hline
\end{tabular}

Table 3. Baseline patient characteristics

\begin{tabular}{|c|c|c|c|c|c|c|}
\hline & PID 001 & PID 002 & PID 003 & PID 004 & PID 005 & PID 006 \\
\hline Age, years & 65 & 71 & 69 & 75 & 69 & 70 \\
\hline Gender & $\mathrm{m}$ & $\mathrm{m}$ & $\mathrm{m}$ & $\mathrm{m}$ & $\mathrm{m}$ & $\mathrm{m}$ \\
\hline ECOG performance status & 1 & 0 & 1 & 1 & 0 & 0 \\
\hline Histology & $\begin{array}{l}\text { Adeno- } \\
\text { carcinoma }\end{array}$ & $\begin{array}{l}\text { Adeno- } \\
\text { carcinoma }\end{array}$ & $\begin{array}{l}\text { Adeno- } \\
\text { carcinoma }\end{array}$ & $\begin{array}{l}\text { Adeno- } \\
\text { carcinoma }\end{array}$ & $\begin{array}{l}\text { Adeno- } \\
\text { carcinoma }\end{array}$ & Squamous \\
\hline Disease stage & IV & IV & IV & IV & IV & IV \\
\hline Previous treatment & & & & & & \\
\hline $\begin{array}{l}\text { Chemotherapy } \\
\text { Other }\end{array}$ & $\begin{array}{l}\text { Gem/Carbo } \\
\text { Radiation }\end{array}$ & Gem/Carbo & $\begin{array}{l}\text { Pacl/Carbo } \\
\text { Radiation CNS }\end{array}$ & Gem/Carbo/Beva & Pacl/Carbo & Gem/Carbo \\
\hline
\end{tabular}

PID = Patient identification; CNS = central nervous system; Gem = gemcitabine; Carbo = carboplatin; Pacl = paclitaxel; Beva = bevacizumab. 
Kroeber et al:: Combination Chemotherapy with Docetaxel and Pemetrexed as Second-Line Treatment in Patients with Stage IIIB/IV Non-Small Cell Lung Cancer

Table 4. Treatment-related grade $3 / 4$ adverse events (all cycles)

\begin{tabular}{|c|c|c|c|c|c|c|}
\hline & PID 001 & PID 002 & PID 003 & PID 004 & PID 005 & PID 006 \\
\hline Emesis & & & & & III & \\
\hline Dyspnea & & & & & III & \\
\hline Allergic reaction & & III & & & & \\
\hline Anorexia & & & & & III & \\
\hline Fatigue & & & III & & & \\
\hline Diarrhea & & & & III & & \\
\hline Rash & & III & & & & \\
\hline Stomatitis/mucositis & & & III & & III & III \\
\hline Alopecia & & & & & III & \\
\hline Febrile neutropenia & & & & & & III \\
\hline
\end{tabular}

PID = Patient identification

Table 5. Outcome data summary

\begin{tabular}{lllll}
\hline Patient ID & Cycles & End of therapy due to & Best response & Time to PD \\
\hline 001 & 1 & Death & PD & $<3$ months \\
002 & 1 & Toxicity & NE & $>3$ months \\
003 & 1 & Toxicity & NE & $<3$ months \\
004 & 1 & Death & PD & $<3$ months \\
005 & 1 & Toxicity & NE & $<3$ months \\
006 & 1 & Toxicity & PD & $<3$ months \\
\hline
\end{tabular}

ID = Identification; NE = not evaluable. 